\title{
Long Term Temperature Trends at Major, Medium, Small Cities and Hill Stations in India during the Period 1901-2013
}

\author{
Dilip Rajaram Kothawale"1, Nayana Rajendra Deshpande', Rupa Kumar Kolli2 \\ ${ }^{1}$ Indian Institute of Tropical Meteorology, Pune, India \\ ${ }^{2}$ World Climate Applications \& CLIPS Division, World Meteorological Organization, Geneva, Switzerland \\ Email: kotha@tropmet.res.in
}

Received 10 May 2016; accepted 30 August 2016; published 2 September 2016

Copyright (C) 2016 by authors and Scientific Research Publishing Inc.

This work is licensed under the Creative Commons Attribution International License (CC BY).

http://creativecommons.org/licenses/by/4.0/

(c) (i) Open Access

\begin{abstract}
Industrialization and urbanization are the most dominant causal factors for long-term changes in surface air temperatures. To examine this fact, the long term changes in the surface-air temperatures have been evaluated by the linear trend for the different periods, i.e. 1901-2013, 1901-1970 and recent period 1971-2013 as rapid industrialization was observed during the recent four decades. In the present study, seasonal and annual mean, maximum and minimum temperature data of 36 stations for the period 1901-2013 have been used. These stations are classified into 4 groups, namely major, medium, small cities and hill stations. During the period 1901-1970, less than 50\% stations from each group showed a significant increasing trend in annual mean temperature, whereas in the recent period $1971-2013$, more than $80 \%$ stations from all the groups except small city group showed a significant increasing trend. The minimum temperature increased faster than that of the maximum temperature over major and medium cities, while maximum temperature increased faster than the minimum temperature over the small cities and hill stations. The annual mean temperature of all the coastal stations showed a significant increasing trend and positive correlation with Precipitable Water Vapour (PWV). The effect of PWV is more pronounced on minimum temperature than that of the maximum.
\end{abstract}

\section{Keywords}

Increasing Trend, Decreasing Trend, Temperature Anomalies, Aerosol Index, Precipitable Water Vapour

\section{Introduction}

Atmospheric temperature is one of the most important characteristics of the climate system and widely used as a

How to cite this paper: Kothawale, D.R., Deshpande, N.R. and Kolli, R.K. (2016) Long Term Temperature Trends at Major, Medium, Small Cities and Hill Stations in India during the Period 1901-2013. American Journal of Climate Change, 5, 383398. http://dx.doi.org/10.4236/ajcc.2016.53029 
measure of climate change on regional, hemispheric as well as global scales. The fourth and fifth Assessment Report (AR4 and AR5) of the Intergovernmental Panel on Climate Change [1] [2] reported that the global mean surface air temperature has increased by $0.74^{\circ} \mathrm{C}$ and $0.8^{\circ} \mathrm{C}$, respectively in the past century. Greenhouse effect causing global warming is one of the theories that explains the warming is due to increasing concentration of greenhouse gases in the atmosphere after the industrial revolution.

However, in context of global warming, regional manifestation of temperature variations assume special importance as warming is not uniform across the globe. Hence, many researchers have studied temperature variability of all-India and regional scales. Rupa Kumar et al. [3] pointed out that while the mean temperature trends over India were similar to the global and hemispheric trends, the diurnal asymmetry of surface air temperature trends observed over India is quite different from that noted in the other parts of the world [4]. Krishnan and Ramanathan [5] suggested that all-India surface air temperature during the drier part of the year (January-May) has been subjected to a relative cooling by as much as $0.3^{\circ} \mathrm{C}$ during the last three decades (1968-1997), when the global effects of greenhouse gases and natural variability are filtered out from the temperature series. However, Kothawale and Rupa Kumar [6] have pointed out that, this is rather a perceived cooling, and mentioned that both all-India annual maximum and minimum temperatures have significantly increased during the recent 3 decades (1971-2003) and accelerated warming is observed after 1990. Kothawale et al. [7] studied the all-India and global temperature variability using the data for the period 1901-2007 and reported that all-India mean temperature have significantly increased by $0.51^{\circ} \mathrm{C}$ while global annual mean temperature increased by $0.76^{\circ} \mathrm{C}$ per 100 years, They also reported that the magnitude of the warming trend of winter and post-monsoon seasons were almost the same for the Globe and India, while pre-monsoon and monsoon temperature trends for India were half that of the global trend. The regional climate study also projected significant warming over India towards the end of the $21^{\text {st }}$ century [8]. Like greenhouse gases, aerosols also play important role in surface air temperature variability. Aerosols are responsible for lowering of land surface temperature, i.e. cooling effect which restricts the warming effect of greenhouse gases. Keeping this view, Kothawale et al. [9] have studied the aerosol effect on regional temperatures and reported that during the period 1950-1990 dry season (November to May) maximum temperature showed decreasing trend over North India (Aerosol optical depth is high over this region), while notable positive trend was observed during the period 1991-2007. On the other hand, South India temperature showed positive trend in the wet (June-September) as well as dry seasons for the same period. The negative radiative forcing of aerosols dominates the temperature trends over North India during 1951-1990, and after 1991, it appears that the atmospheric concentration of greenhouse gases may be more than compensating the aerosol related cooling and hence warming trend was observed. The global phenomena like El-Nino Southern Oscillation (ENSO) also affects the regional temperature variability [7] [10] [11].

Local/station temperature is one of the major climatic elements to record the changes in the atmospheric environment. Whatever pollutant gases, particulate matter or waste heat, those are produced as a result of urbanization and industrialization affect the local climate. Rupa Kumar and Hingane [12] studied long term variations of seasonal and annual surface air temperatures at 6 industrial and non-industrial cities and reported out of 6 industrial cities only 3 cities showed a significant warming trend while non-industrial cities did not show a significant trend. However, this study is based on a few stations with data period prior to 1990. Whereas, accelerated warming was observed over India after 1990 [6]. A similar study has been carried out by Dhorde et al. [13] for the 4 largest cities in India and reported that out of 4, 3 cities showed a significant increasing trend in annual mean temperature. On daily time scale, Rao et al. [14] examined the effect of urbanization on meteorological parameters for 15 cities with a population more than one million. They reported that the percentage number of days of maximum temperatures $>35^{\circ} \mathrm{C}$ and minimum temperatures $<10^{\circ} \mathrm{C}$ are decreasing and increasing respectively, over north India, while maximum temperature days are increasing over south India, during the period 1969-1999. Mohan et al. [15] examined trends in annual and seasonal maximum, minimum and mean temperatures of four meteorological stations of National Capital Region of India, namely Safdarjung, Palam, Gurgaon and Rohatak for the period 1965-2005. They found the annual mean maximum temperature did not show any specific trend; however a consistent increasing trend was seen in annual mean minimum temperature. Jaganathan and Andimuthu [16] studied the temperature variability at Chennai, the fourth largest metropolitan city in India and reported a significant increase in annual mean, maximum and minimum temperatures during the period 1950-2010.

Most of the previous studies were based on the few stations with data period prior to 2000, while a very few studies are available on temperature variability at hill stations. Accelerated warming over India was observed 
after 1990. With this view, the present study analyses trends in temperature of major, medium, small cities, and hill stations for the different periods, i.e. 1901-2013, 1901-1970 and 1971-2013 to see the effect of industrialization/urbanization.

\section{Data and Method of Analysis}

The monthly mean (average of maximum and minimum), maximum and minimum surface air temperature data of 36 stations, well distributed over the country, have been used in the present study, covering the period 110 to 113 years (1901-2013). These stations are classified into 4 groups viz., major, medium, small cities and hill stations. Out of 4 groups, first 3 groups are based on the updated information of total population [17]. The details of the stations are given in Table 1. The classification of cities is similar to that of Ren et al. [18] and Rupa Kumar et al. [12]. Stations with altitude more than $1000 \mathrm{~m}$ are considered as hill stations

(https://en.wikipedia.org./wiki/Hill_station). In the present study, out of 36 stations, 17 are located in North India (north of $20^{\circ} \mathrm{N}$ ) and 19 stations in South India (south of $20^{\circ} \mathrm{N}$, Figure 1). The stations are classified as follows, into following 4 groups:

Major city: Station population $>2,000,000$;

Medium City: Station population $>400,000$ and $<2,000,000$;

Small city: Station population $<400,000$;

Hill Station: Station altitude $>1000 \mathrm{~m}$.

The temperature data for the period 1901-1990 were obtained from India Meteorological Department (IMD) Pune, and the monthly data for the period 1991-2013 were computed from the daily data reported in the Indian

Table 1. Details of the stations used in this study (station abbreviation given by India Meteorological Department are in bracket, hill station altitude in meters in bracket).

\begin{tabular}{|c|c|c|c|c|c|c|c|}
\hline & Station Name & Data period & Population & & Station Name & Data period & Population \\
\hline \multicolumn{7}{|c|}{ Major city } & Small city \\
\hline 1 & Delhi (DLH) & 1901-2011 & $11,007,835$ & 1 & Ambala (AMB) & 1901-2010 & 196,216 \\
\hline 2 & Kolkata (CAL) & 1901-2010 & 4,486,679 & 2 & Tezpur (TZP) & 1901-2013 & 105,377 \\
\hline 3 & Lucknow (LKN) & 1901-2010 & $2,815,601$ & 3 & Dibrugarh (DBH) & 1901-2013 & 138,661 \\
\hline 4 & Jaipur (JPR) & 1901-2010 & $3,073,350$ & 4 & Jagdalpur (JGD) & 1901-2010 & 125,645 \\
\hline 5 & Ahmadabad (AHM) & 1901-2012 & $5,570,585$ & 5 & Ratanagiri (RTN) & 1901-2010 & 76,239 \\
\hline 6 & Surat (SRT) & 1901-2012 & $4,462,002$ & 6 & Akola (AKL) & 1901-2012 & 427,146 \\
\hline 7 & Mumbai (BMB) & 1901-2013 & $12,478,447$ & 7 & Bijapur (BJP) & 1901-2012 & 326,360 \\
\hline 8 & Pune (PNA) & 1901-2013 & $3,115,431$ & 8 & Cuddalore (CDL) & 1901-2012 & 173,361 \\
\hline 9 & Nagpur (NGP) & 1901-2010 & $2,405,421$ & 9 & Masulipatnam (MPT) & 1901-2010 & 170,008 \\
\hline 10 & Bengaluru (BNG) & 1901-2012 & $8,425,970$ & 10 & Mangalore (MNG) & 1901-2010 & 484,785 \\
\hline 11 & Hyderabad (HYD) & 1901-2010 & $6,809,970$ & & & & \\
\hline 12 & Chennai (MDS) & 1901-2012 & $4,681,087$ & & & & \\
\hline \multicolumn{5}{|c|}{ Medium city } & \multicolumn{3}{|c|}{ Hill stations } \\
\hline 1 & Guwahati (GHT) & $1901-2010$ & 963,429 & & & & \\
\hline 2 & Jodhpur (JDP) & 1901-2012 & $1,033,918$ & 1 & Srinagar (SRN) & 1901-2013 & 1,192,792 (Ht. 1587 ) \\
\hline 3 & Agra (AGR) & 1901-2010 & $1,574,542$ & 2 & Simala (SML) & $1901-2010$ & 169,758 (Ht. 2202 ) \\
\hline 4 & Jhanshi (JHN) & $1901-2010$ & 507,293 & 3 & Darjeeling (DJG) & 1901-2010 & 120,414 (Ht. 2128 ) \\
\hline 5 & Raipur (RPR) & 1901-2010 & $1,010,087$ & 4 & Medikeri (MRC) & 1901-2012 & 33,318 (Ht. 1061) \\
\hline 6 & Allahabad (ALB) & $1901-2010$ & $1,117,094$ & 5 & Kodaikanal (KDK) & 1901-2012 & 36,501 (Ht. 2133) \\
\hline 7 & $\begin{array}{l}\text { Coimbatore } \\
\text { (CMB) }\end{array}$ & 1901-2010 & $1,061,447$ & & & & \\
\hline 8 & Mysore (MSR) & 1901-2010 & 887,446 & & & & \\
\hline 9 & $\begin{array}{c}\text { Tiruanthapurm } \\
\text { (TRV) }\end{array}$ & 1901-2012 & 752,490 & & & & \\
\hline
\end{tabular}




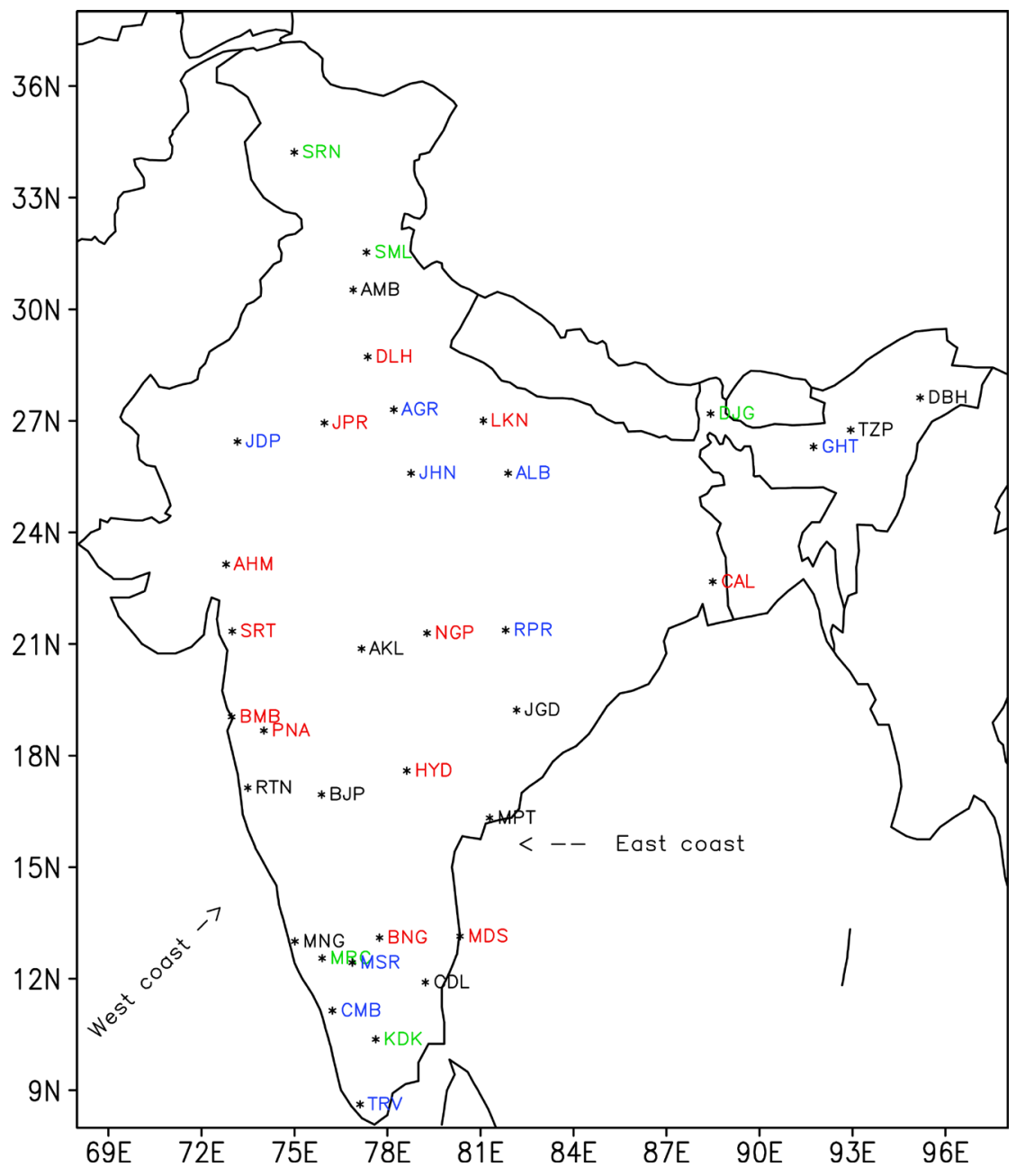

Figure 1. Network of 36 stations include major (red), medium (blue), small (black) cities and hill stations (green colour).

Daily Weather Reports (IDWRs) of IMD. Adequate care has been taken in ensuring the homogeneity of the data. The outliers in the monthly temperature data were identified as such if the station's monthly temperature values were greater/lesser than the long term mean by \pm 3 times standard deviations of the corresponding month [3]. The identified outliers were compared with the nearest station data and then ensured that it was really outlier or not. The outliers identified in this manner have been considered as missing data and these account for less than 5\% of the total number of data points. The missing values were then interpolated using the data from the neighboring stations by a regression technique [3], as well as inverse distance squared weighted average algorithm [6].

To examine the impact of spatial variability of aerosol loading on temperature over the different parts of the country, the annual aerosol index (AI)/aerosol optical depth (AOD) series were prepared for North (north of $20^{\circ} \mathrm{N}$ ) and South (south of $20^{\circ} \mathrm{N}$ ) India for the period 1979-2013. AI data for the period 1979-1992 were obtained from the TOMS instrument, Nimbus-7. The data for the period 1993-1996 are not available; the data for the period 1997-2005 were obtained from Earth Probe Satellite

(ftp://toms.gsfc.nasa.gov./pub/eptoms/data/aerosol/). 2005 onwards data are not available on this site. Hence, aerosol data in the form of AOD for the period 2005 to 2013 were obtained from MODIS Terra and Aqua monthly level-3 data (http://gdata/sci.gsfc.nasa.gov/daac-bin/G3/guicgi?instance id=MODIS-Monthly L3). The aerosol data have been obtained from different sources for the above mentioned periods, hence separate series have been prepared for those particular periods and examined the aerosol variations. To see the relationship between water vapour (one of the major greenhouse gas) and surface temperature along the coasts. Annual precipitable water vapour series for East, West coast of India ( East and West coast area taken from Kothawale et al. [7]) have been prepared for the period 1971-2013 by taking the arithmetic average of grids $\left(2.5^{\circ}\right.$ Long $\times 2.5^{\circ}$ 
Lat.) along the coasts. The precipitable water vapour series is also prepared for North India (north of $20^{\circ} \mathrm{N}$ ) as it is away from the coasts (Figure 1). Data source for the precipitable water vapour is IRI data Library

(http://iridl.ldeo.columbia.edu/SOURCES/.NOAA/.NCEP-NCAR/.CDAS-1/.MONTHLY/)

For monthly temperature, adequate care has also been taken regarding the homogeneity of the data. The possible inhomogeneities in the data were first assessed by visual examination (sudden high/low value) of the plots of the monthly and annual mean maximum and minimum temperature series at each station. Very few stations showed a strong abrupt change in the series, and were promptly deleted from further analysis. The homogeneity of the data was also examined by using the RHtest (http://cccma.seos.uvic.ca/ETCCDMI/), however inhomogeneity was not found in any station. Further quality control measures were also taken up to identify errors in data archiving processes, such as keying or printing errors. For daily temperatures, quality controls are used as given by Kothawale et al. [7].

The following procedures were used to identify errors/outliers in the data sets:

- For the daily temperatures, both maximum and minimum temperatures are considered to be missing if daily maximum temperature is less than the daily minimum temperature.

- On any given day, if the temperature differs by $\pm 10^{\circ} \mathrm{C}$ or more from the previous day as well as the next day, then the value is considered as a potential outlier [7]. Whether the value can be really treated as an outlier or not was then determined by examining the weather situation on that day, and if there is no supporting evidence to the anomaly, it is treated as missing value.

In the daily temperature data sets, the proportion of missing values (actually missing in the data sets as well as outliers treated as missing) at individual stations ranges from $0 \%$ to $5 \%$ during the period $1970-2013$. These missing values in the data sets have been filled by using appropriate methods as indicated below:

- If the daily temperatures were nearly uniform from 3 to 4 days before and after a given day with missing temperature data, the weather situation on that missing date was also normal, then the missing value was filled with the average of the temperatures on the preceding and the following day of the missing date.

- Other missing daily temperature values have been objectively interpolated by using an inverse squared distance weighted average algorithm. The procedure of this algorithm is given by Kothawale and Rupa Kumar [19]. The total number of such interpolated values is less than $5 \%$ of the total number of data points.

To examine the anthropogenic changes in temperatures, natural variability has been removed by computing monthly temperature anomalies for all the 36 stations for the available period. The monthly average temperature anomaly series of each group is constructed by taking arithmetic average of monthly anomaly series of all the stations in the respective group. The annual and seasonal; winter (previous year December + January + February, DJF), Pre-monsoon (March + April + May, MAM), monsoon (June + July + August + September, JJAS) and post-monsoon (October + November, ON) temperature series for all the stations, four groups and precipitable water vapour series for East, West coast and North India were prepared.

Annual and seasonal temperature series of 36 stations were examined for long term variations in different sub periods viz., 1901-2013, 1901-1970 and 1971-2013. These sub-periods are based on the study of Kothawale et al. [9]. In the text, we mentioned the data period as 1) recent period: 1971-2010 (or 2013), past period; 101-1970 and entire period: 1901-2010 (or 2013). The trend is quantified by the slope of a simple linear regression fitted to each of the time series. The statistical significance of the trend is assessed by Mann Kendall rank statistics test.

\section{Temperature Trends at Major, Medium, Small Cities and Hill Stations}

\subsection{Major Cities}

In the present study trends in mean, maximum and minimum temperatures at 12 major cities have been examined to see the variability on different time scales as mentioned above. 6 stations show a significant increasing trend in annual mean temperature during the period 1901-2013, however during the recent period 1971-2013, most of the stations (10) show a significant increasing trend and the remaining stations namely Surat and Lucknow show increasing tendency (trend not statistically significant, Figure 2). Surat is the largest manufacturer of cotton industries in India and the biggest centre for man-made fabrics (Wikipedia). A number of textile and polyfiber factories in Surat produce abundant aerosols in the atmosphere which may dominate the temperature trend by negative radiative forcing. Lucknow is situated in Gangetic Plain. Aerosol concentration is higher over Gangetic plain than the rest of the country [20] [21]. Lal et al. [22] also showed an increasing trend in aerosol 

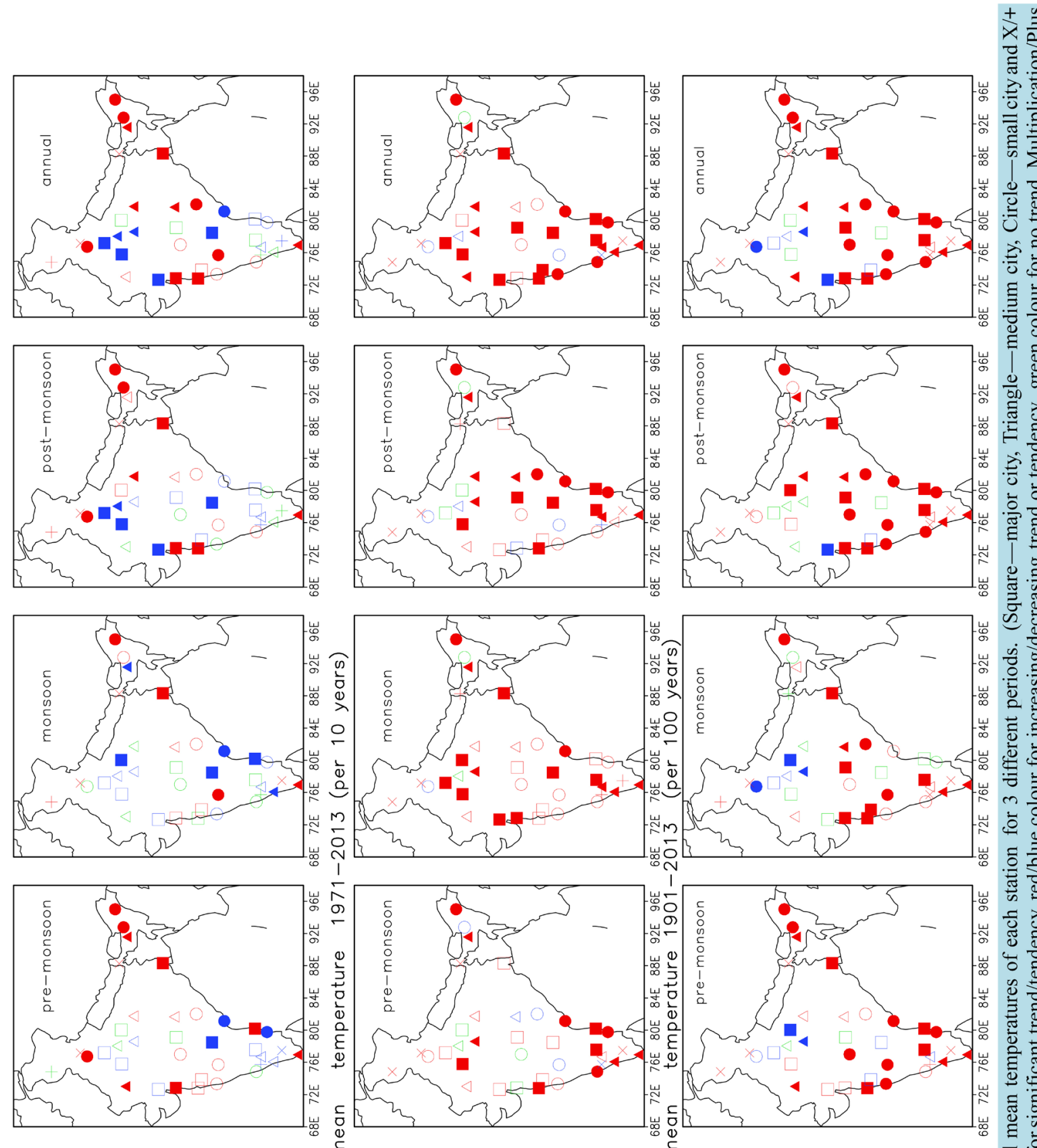

焉

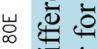
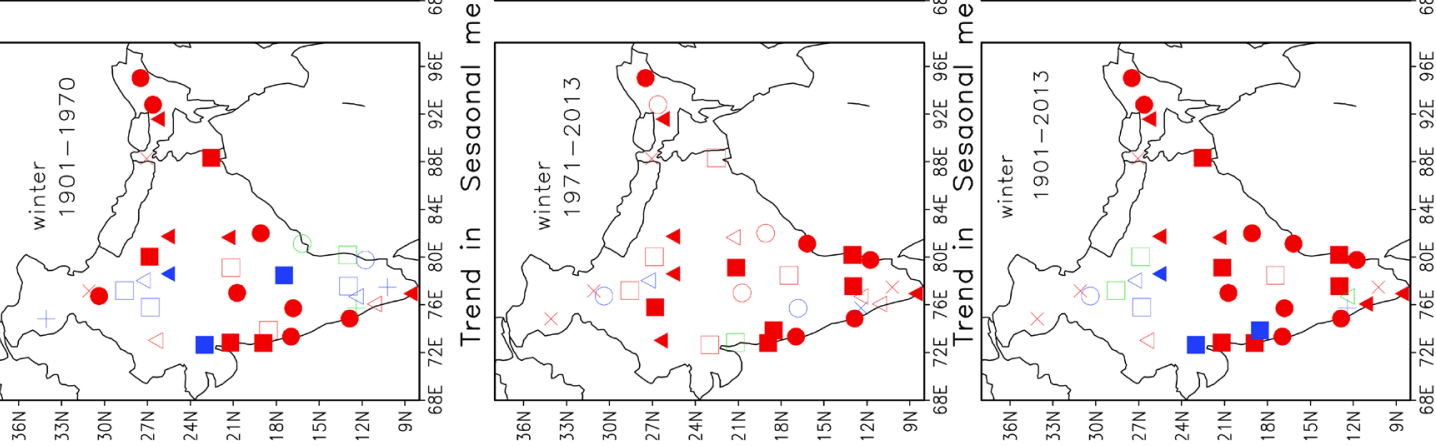

ำ

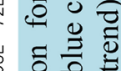
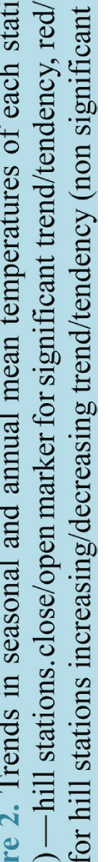
index over Gangetic plain during the period 1979-2010. Higher aerosol concentration prevents to surface air temperature warming [9]. Most of the cities in Gangetic plain or North of $20^{\circ} \mathrm{N}$ (Figure 1) are experiencing a decreasing trend over the entire period (trend statistically not significant), however, they are experiencing a significant increasing trend in the recent period. Higher concentration of aerosols over the northern part of India plays important role in the surface temperature cooling. In view of this, annual aerosols variation over the South and North India have been examined (Figure 3). Aerosols are much higher over the North India than the South India. Yearly aerosol index is varying between 1 to 1.5 and 0.5 to 1.0 over North and South India respectively, during the period 1978 to 2013. Both the aerosols series show the increasing trend during the period 1978-2013, however, after 2005 the rate of increase is reduced. The negative radiative forcing of aerosols may dominate the temperature over northern India, however during the recent period, atmospheric concentrations of greenhouse gases may be more compensating the aerosol related cooling, hence increasing trend is observed.

During the entire period, significant increasing trends are observed in annual mean temperatures due to significant increase in both maximum and minimum temperatures or by maximum temperature (Figure 4, Figure 5). In the recent period, trend is mainly because of minimum temperature (Figure 5). Most of the stations (9)
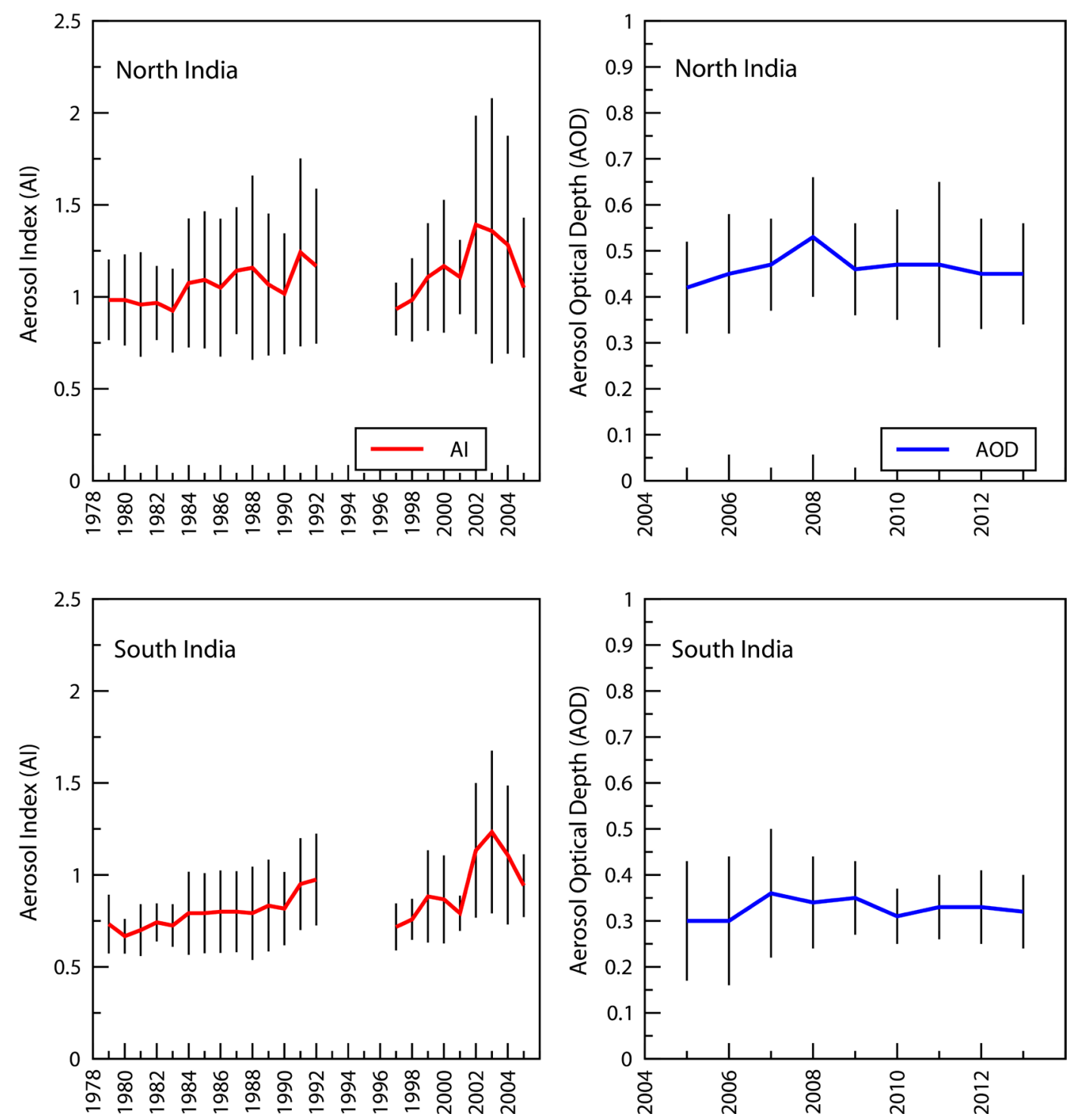

Figure 3. Variation of annual aerosol index (AI)/aerosol optical depth (AOD) over the North and South India during 19792013 (1993-1996 data not available, 2000 onwards AOD MODIS data is available, vertical bars show the standard deviation). 

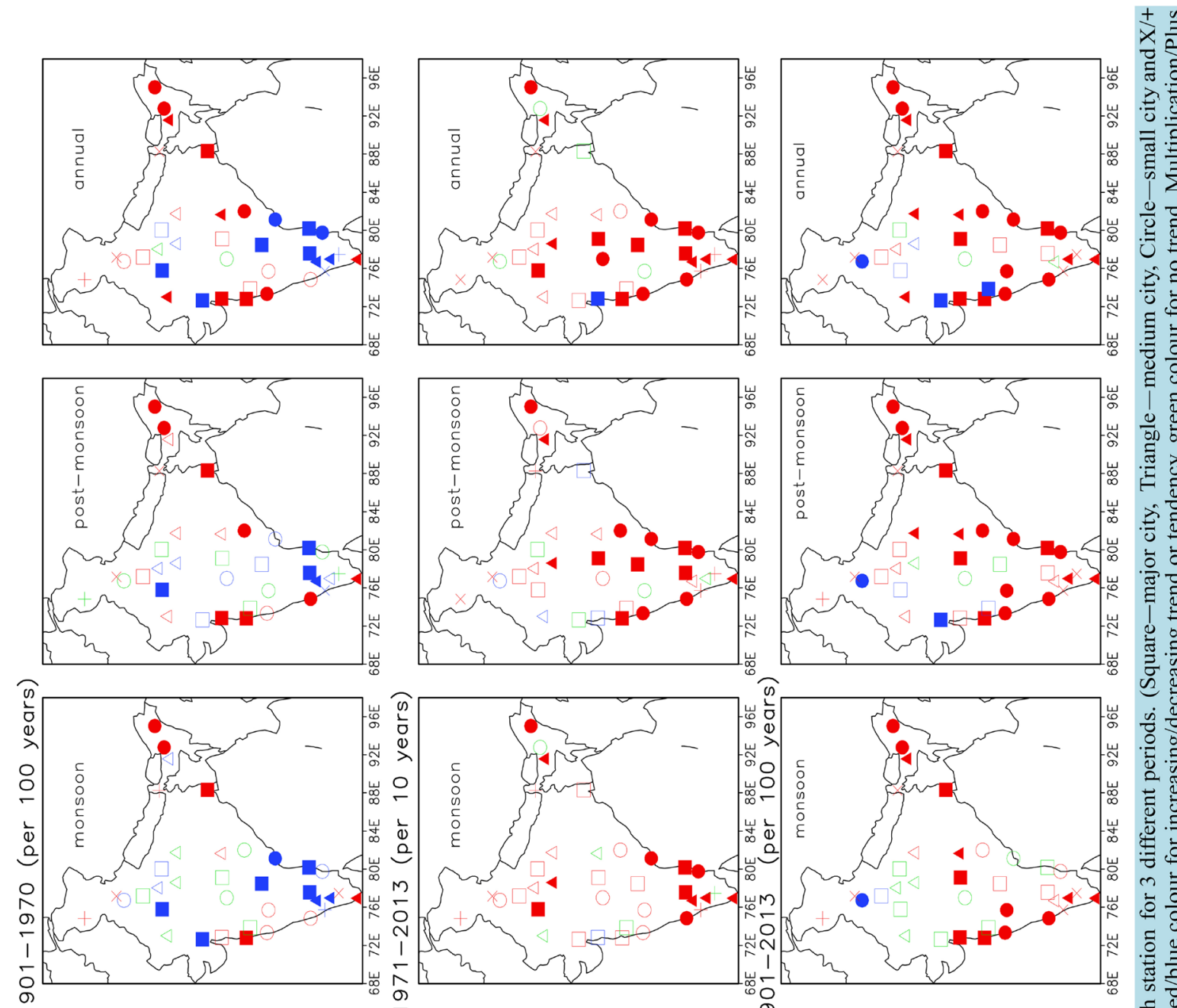

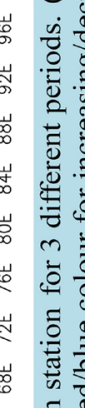
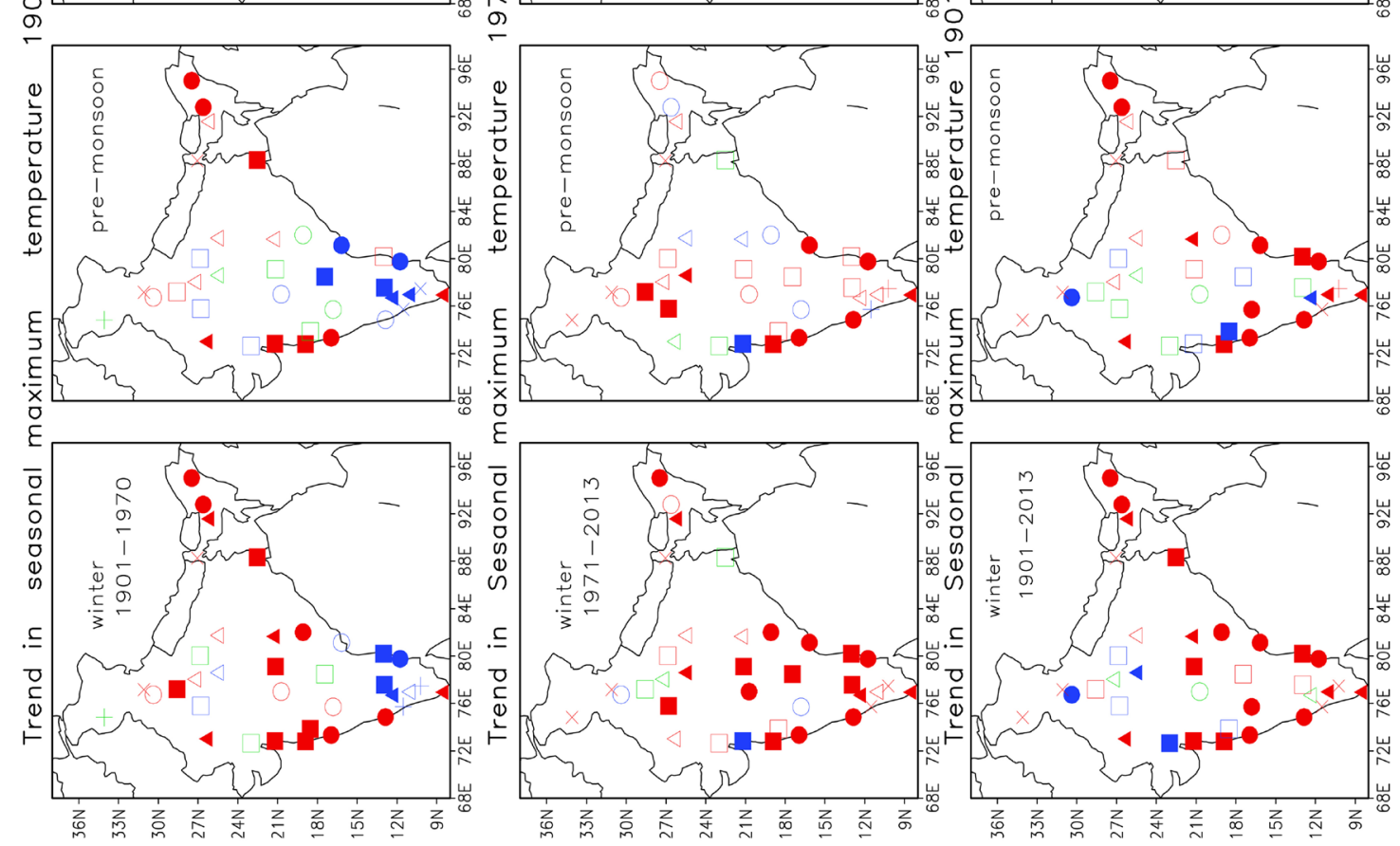

동

षें

岕

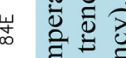

एक

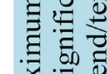

峞

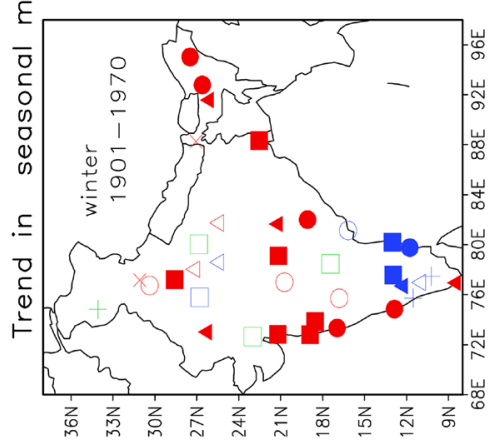

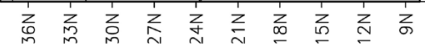

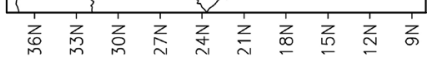

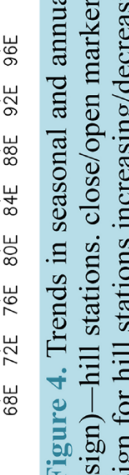

कृष्ठ है 

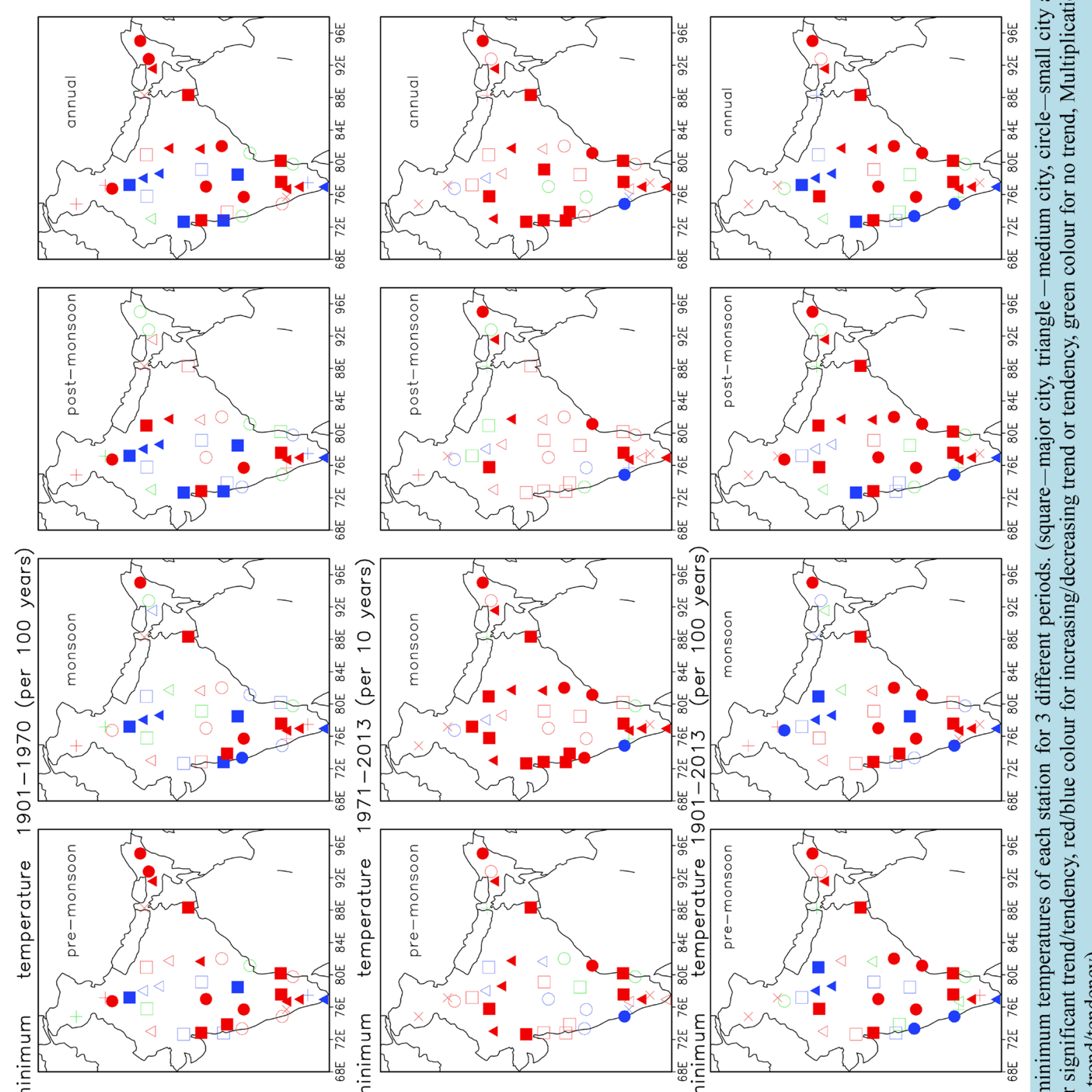

\section{$+\stackrel{n}{x}$
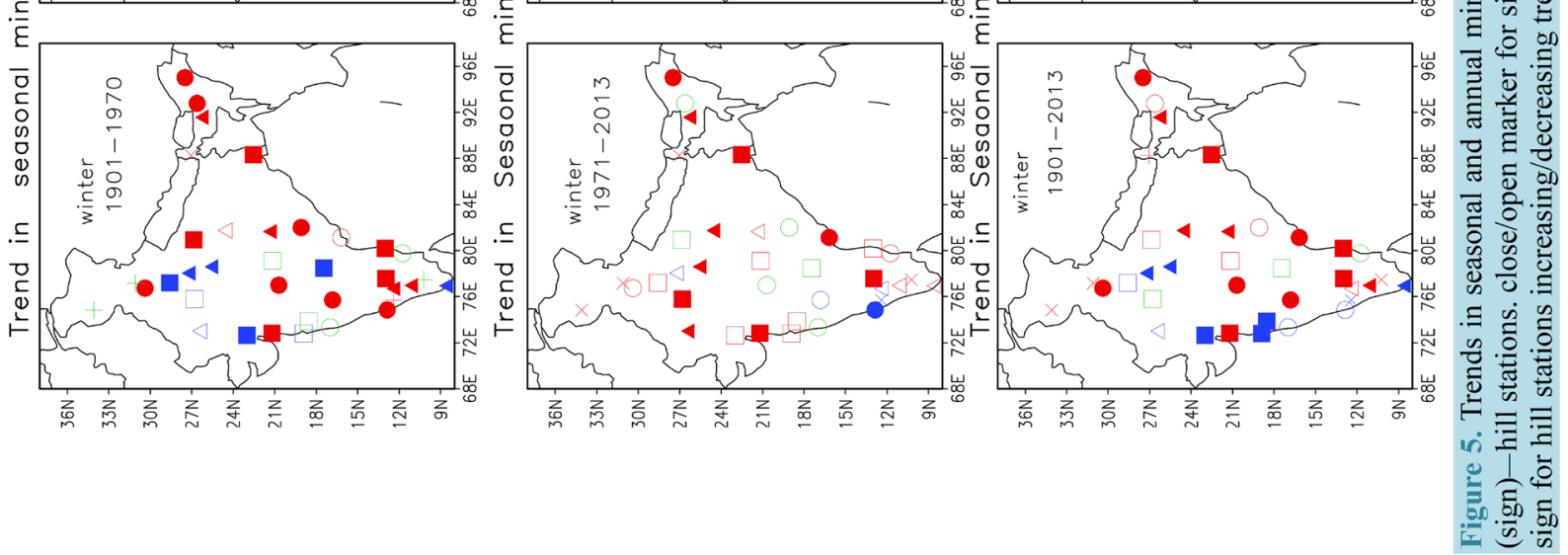
show significant increasing trends in minimum temperature, whereas the maximum temperature shows a significant increasing trend at 6 stations. It is to be noted that during the past period 1901-1970, when urbanization was not rapid, only 3 stations show a significant increasing trend while 4 stations show decreasing trend (Figure 2). Annual mean temperature anomaly series of major city group also shows the almost no trend up to 1970 and thereafter temperature is sharply increasing up to the year 2010 (significant trend $0.18^{\circ} \mathrm{C} / 10$ years, Figure 6). The analysis reveals the significant role of urbanization in rising the temperatures at most of the major cities, in the recent period. The urbanization effects are more pronounced for minimum temperature than that of maximum temperature. High concentration of multistory buildings obstructs the short wave radiations coming from the sun during the daytime and put sort of hindrance for outgoing long wave radiations to the sky. This causes lowering of day and rising of night temperatures. Wilbanks and Kates [23] also reported that the effect of urbanization is mostly reflected in minimum temperature.

On the seasonal scale, during the entire period, winter and post monsoon maximum temperatures of relatively more no. of stations (5) from south India show significant increasing trends than the other seasons (Figure 4). In the recent period winter and post monsoon temperatures increase at 6 stations, and most of the remaining stations show warming tendency. Very few stations in northern part India show cooling tendency (trend not significant). It is important to note that minimum temperature significantly increase at maximum no. of stations (9) during the monsoon season, whereas maximum temperatures increase significantly at only 3 stations (Figure 4, Figure 5).

The major cities Delhi, Lucknow, Jaipur and Ahmadabad are thickly populated with skyscrapers at many places and industrialized cities, however, they show a decreasing trend (not statistically significant) in annual mean temperature during the entire period. While, all the major cities along the coasts show a significant increasing trend in almost all the seasons for the periods 1971-2013 and 1901-2013 (Figure 2 and relevant explanation are given in section 4). The marked differences in the temperature trends at the stations are determined more by the location of the stations with respect to the broad areas of increasing/decreasing trends observed over India rather than the stations being highly industrialized/non-industrialized [12].

\subsection{Medium Cities}

Temperature data of 9 medium cities, well spread over the country, were used in the present analysis. The number of medium cities (6) showing statistically significant increasing trend in annual mean temperatures during the entire period is more than that of the major cities. However, in the recent period there is a rise in stations showing significant increasing trends (7 stations, Figure 2). It is to be noted that out of 9 stations, 3 are in South India, and all of them show a significant increasing trend, and out of remaining 6 stations from North India, 4 stations show a significant increasing trend. In the past period (1901-1970), only 4 stations show the significant increasing trend (Figure 2). From the analysis, it is seen that the urbanization effects on temperature is not uniform at all the stations. It may be due to location of stations, spatial temperature variability, aerosol optical depth over that region as well as agricultural cropping patterns [24]. In the recent period, both maximum and minimum temperatures show a significant increasing trend at 5 stations, but the stations at which both temperatures show a significant increasing trend are very few (2 stations) and they are located in Southern part of India.

Seasonal maximum temperatures significantly increase at 5 stations during the entire period, and remaining stations show increasing/decreasing tendency, and these stations are in the northern part of India (Figure 4). In the case of the minimum temperature, only winter and post monsoon season temperatures show a significant increasing trend at 4 and 5 stations respectively (Figure 5). In the recent period, no station shows a significant decreasing trend in seasonal maximum as well as minimum temperatures. It is important that the maximum number of stations (7) shows a significant increasing trend in monsoon season minimum temperature while only 4 stations show a significant increasing trend in monsoon season maximum temperature. Annual mean temperature anomaly series of medium city group shows a sharp increasing trend after 1985 than the maximum temperature (Figure 6). The trend is mainly contributed by minimum temperature.

\subsection{Small Cities}

Based on the population criteria, 10 small cities are considered in the present study. Industries in these cities are very less or nil. Almost all the stations (9), show the significant increasing trend in annual mean temperatures during the entire period, and only one station Ambala, which is located in the northwest part of India (Figure 1), 

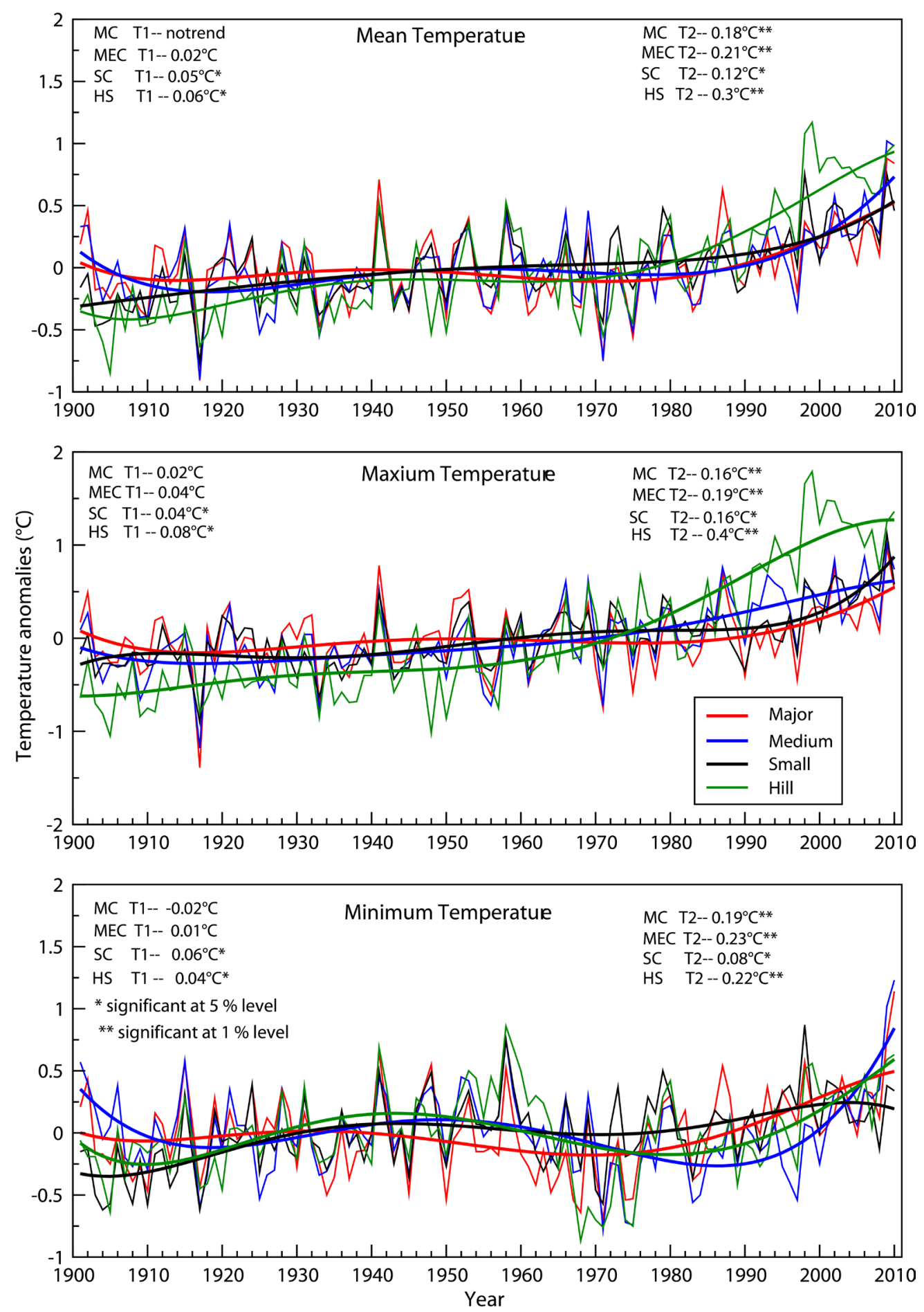

Figure 6. Variations in averaged annual mean, maximum and minimum temperatures anomalies series of major, medium, small cities and hill stations groups $\left(5^{\text {th }}\right.$ Degree polynomial fitted to each series, MC — major city, MEC-medium city, SCsmall city, HS-hill station. T1 and T2 trend for 1901-1970, 1971-2010, trend per 10 years).

shows a significant decreasing trend (Figure 2). The detailed analysis of Ambala station shows rise in temperature up to 1950 and sharp decrease thereafter up to 2000 and again slowly increase thereafter (Figure not shown). Along with decreasing trend, a remarkable decadal variability is also noticed during this period. This may be due to the local effects of irrigated land by the Bhakra Nangal Dam water (1970s). The significant increasing trends 
at above 9 stations are mainly due to significant increase in maximum temperatures. The maximum temperatures significantly increase at 8 stations, whereas the minimum temperatures increase at 5 stations. On the seasonal scale, winter, pre-monsoon and post-monsoon maximum temperatures show a significant increasing trend at maximum number of stations (8) (Figure 4), whereas minimum temperatures significantly increase at 5 stations (Figure 5). The trends in annual mean temperatures have also been examined for the past period and only 5 stations show a significant increasing trend and it is mainly due to significant increasing trend in winter temperature. The analysis reveals that winter temperature increases in all the 3 periods (Figure 2).

In the recent period, only 5 stations show a significant increasing trend in annual mean temperature. Out of these 5, 4 stations are along the coasts or near the coasts, and 1 station in the northeast part of India. Along the coastal belt availability of water vapour (one of the major greenhouse gas) is much higher than that of the interior parts of the country. Annual water vapour series shows a gradual increase after 1995 (Figure 7). It is also to be noted that significant increasing trends are not observed at the stations situated in the interior part of the country, except station Dibrugarh where the significant increasing trend is observed. Though, Dibrugarh falls in the small city group by population criteria, but within the periphery (20 to $30 \mathrm{~km}$ ) of Dibrugarh, there are oil refineries, thermal power plants and other industries and these factors may cause to rise in temperature. Trends in seasonal and annual maximum and minimum temperatures are up to some degree different from mean temperature. Maximum temperature of winter and post monsoon seasons increase significantly at most of the stations (7, Figure 4), whereas minimum temperatures increase significantly at only 2 stations (Figure 5).

It is also important to note that during the entire period significant increasing trends in annual mean temperatures are observed at 9 stations, whereas in the past and recent periods, significant increasing trends are observed at 5 stations (Figure 2). Hence, we have examined the annual mean temperature time series of all the stations for the entire period (Figures are not shown), and found that nearly 50\% stations showed warming trend from 1901 to 1930 and thereafter temperature stagnated up to 1970 . Decreasing trend/tendency was observed during 19701990. From 1990 onwards, all the stations show sharp increasing trends. From the analysis, it is clear that the maximum number of stations shows the significant warming trend during the entire period due to the decadal variability within the series.

Annual maximum temperature anomaly series of small city group shows a significant increasing trend of $0.16^{\circ} \mathrm{C}$ per 10 years, whereas the minimum temperature shows very little trend of $0.08^{\circ} \mathrm{C}$ per 10 years for the recent period (Figure 6). Over the small cities, concentration of greenhouse gases which help to increase the minimum temperature is less than the major cities.

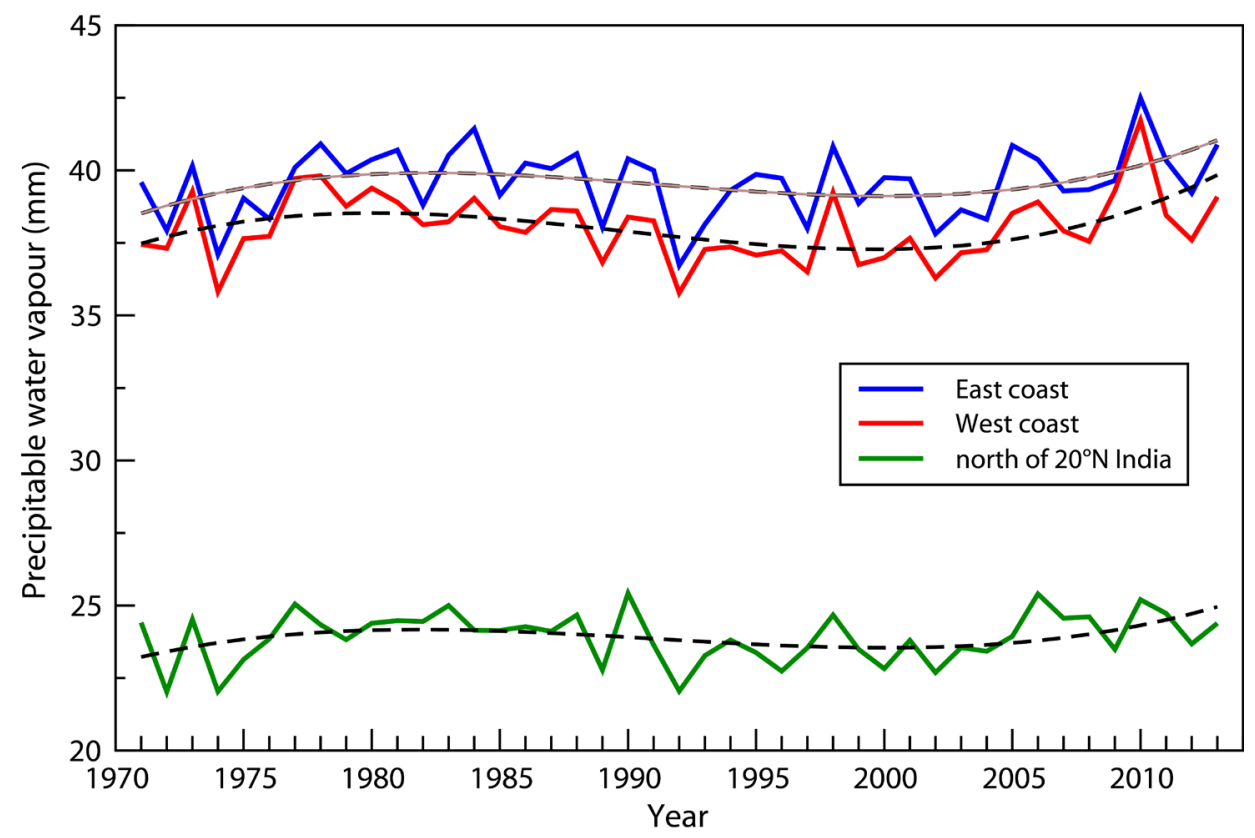

Figure 7. Variation in annual precipitable water vapour over the west, east coast of India and North India during 1971-2013 (Third degree polynomial is fitted to all the series). 


\subsection{Hill Stations}

Five hill stations (as defined in the methodology) are used in this study 3 stations located in North India and 2 stations in South India. All the hill stations show a significant increasing trend in annual mean temperature during the entire period. However, observed trends are mainly due to pronounced warming during the recent period. In the past period 1901-1970, only 2 stations, namely Simla and Darjeeling show a significant increasing trend, whereas 3 stations Srinagar, Kodiakanal and Medikeri do not show any trend (Figure 2). In the recent period, 4 stations show a significant increasing trend and only one station Medikeri shows a significant decreasing trend. Winter maximum as well as minimum temperatures increase at all the stations, except one station Kodiakanal, where the minimum temperature shows a significant decreasing trend (Figure 4 and Figure 5), the trend values are significant at the $1 \%$ level. Annual maximum temperature anomaly series of hill station group show a gradual increase up to 1970, and rapid increase during the period 1971-2010, however minimum temperature is trendless up to 1970 and after it shows an increasing trend up to 2010 (Figure 6). The maximum and minimum temperatures are increased by $0.4^{\circ} \mathrm{C}$ and $0.22^{\circ} \mathrm{C}$ per decade respectively during the period $1971-2010$. The analysis reveals that the maximum temperature increase more rapidly than the minimum, over the hill stations.

\section{Precipitable Water Vapour (PWV) and Temperature Variability}

In the earlier section, it is observed that all the stations from all the groups along the West and East coast regions show the significant increasing trend in annual mean temperature during the entire as well as recent period. Keeping the view, the impact of PWV on temperature is examined by computing the simultaneous correlations between seasonal and annual PWV series and temperatures of all the stations along the West and East coast.

Figure 7 shows the variations in the annual PWV over the East, West coast of India and North India during the period 1971-2013. PWV over the East and West coast of India is almost double to that of North India. Annual PWV series of three regions show very little variations during the entire period, however, after 1990, there is slightly increasing trend over all the regions. The annual values of East and West coast of India are varying between 37 to $45 \mathrm{~mm}$ (Standard Deviations (SD) $1.18 \mathrm{~mm}$ and $1.16 \mathrm{~mm}$ ) and North India annual values are varying between 22 to $25 \mathrm{~mm}$ with SD $0.86 \mathrm{~mm}$. Figure 8 shows the simultaneous correlation coefficients (CCs) separately between PWV over West, East coasts and seasonal and annual mean, maximum and minimum temperatures of all the stations located along the coasts. The positive correlations are observed between annual PWV and annual mean temperatures at all the stations and significant CC is observed at only one station Ratnagiri. Significant positive CCs are observed with minimum temperatures of most of the stations. The weak or negative correlations are observed with maximum temperatures of almost all the stations. The effect of PWV is more pronounced on minimum than the maximum temperature. In all the seasons, PWV are positively correlated with temperatures, except monsoon season, where correlations are found negative at almost all the stations (Figure 8). In this season, maximum PWV are condensed into precipitation and produce the cooling effect. The spatial and temporal variability of PWV may be attributed to the rising temperature at coastal stations.

\section{Summary and Conclusions}

Trends in seasonal and annual mean, maximum and minimum temperatures at major, medium, small cities and hill stations have been examined for the three different periods entire period (1901-2013), past period (19011970 ) and recent period (1871-2013). During the past period, less than 50\% stations from each group showed a significant increasing trend in annual mean temperature, whereas in the recent period, more than $80 \%$ stations from all groups except small city group showed a significant increasing trend.

Most of the major cities, 10 out of 12, showed a significant increasing trend and only two cities showed an increasing tendency in annual mean temperature during the recent period, whereas in the past period when urbanization/industrialization was not rapid, only 3 major cities showed increasing trends and the remaining stations showed decreasing, no trend or increasing/decreasing tendency. Major and medium city groups did not show any trend in annual mean temperatures in the past period. However in the recent period significant (at the 1\% level) trend has been observed of $0.18^{\circ} \mathrm{C}$ and $0.21^{\circ} \mathrm{C}$ per 10 years, respectively.

Out of 10, 9 small cities showed an increasing trend in annual mean temperature for the entire period, however, during the past and recent periods only 5 stations showed an increasing trend, indicating stagnation of temperature warming. From the analysis, it is clear that the a maximum number of stations showed the significant increasing trend during the entire period due to the decadal variability within the series. During the entire period, 

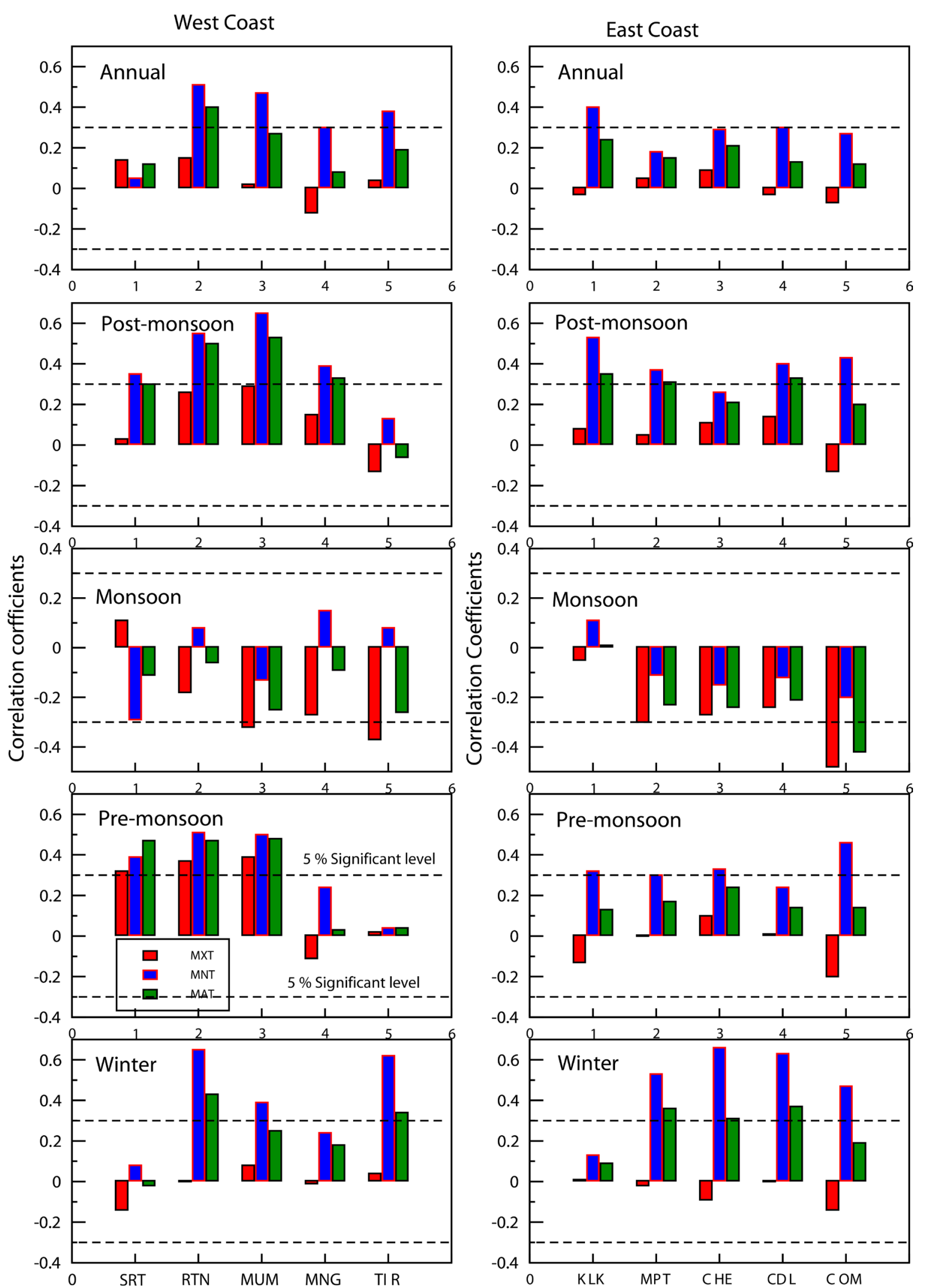

Figure 8. Correlation coefficients between precipitable water vapour over west, east coast and annual and seasonal mean (MAT), maximum(MXT) and minimum (MNT) temperatures of coastal stations. 
most of the stations in South India showed a significant increasing trend compare to North India, however, in the recent period, significant increasing trends/tendencies are observed at almost all stations.

All the stations along the coastal region from all the groups showed the significant increasing trend in annual mean temperature during the entire as well as recent period. Increase in temperature may be attributed to the rising trend in Precipitable Water Vapour over the coasts.

Average annual temperature anomaly series of four groups showed that in the recent period, minimum temperature increases faster than the maximum temperature over major and medium cities, while, maximum temperature increases faster than minimum over small and hill stations. The effect of urbanization on temperature is not uniform at all the stations. It may be due to the location of stations, spatial temperature variability, aerosols optical depth over that region as well as agricultural cropping patterns. The effects of urbanization are more pronounced on minimum temperature than that of the maximum temperature.

\section{Acknowledgements}

The authors are thankful to Dr. R. Krishnan, Director, Indian Institute of Tropical Meteorology (IITM), Pune for providing the necessary facilities for this study. The authors are also grateful to India Met. Department Pune for providing station temperature data.

\section{References}

[1] IPCC 2007 Climate Change (2007) The Scientific Basis, Contribution of Working Group-I to the Fourth Assessment Report of Intergovernmental Panel on Climate Change (IPCC). Cambridge University Press, Cambridge.

[2] IPCC 2013 Climate Change (2013) The Scientific Basis, Contribution of Working Group-I to the Fifth Assessment Report of Intergovernmental Panel on Climate Change (IPCC). Cambridge University Press, Cambridge.

[3] Rupa Kumar, K., Krishna Kumar, K. and Pant, G.B. (1994) Diurnal Asymmetry of Surface Temperature Trends over India. Geophysical Research Letters, 21, 677-680. http://dx.doi.org/10.1029/94GL00007

[4] Karl, T.R., Jones, P.D., Kukla, G., Plummer, N., Razuvayev, V., Gallo, K.P., Lindseay, J., Charlton, R.J. and Peterson, T.C. (1993) A New Perspective on Recent Global Warming: Asymmetric Trends of Daily Maximum and Minimum Temperature. Bulletin American.

[5] Krishnan, R. and Ramanathan, V. (2002) Evidence of Surface Cooling from Absorbing Aerosols. Geophysical Research Letters, 29, 54. http://dx.doi.org/10.1029/2002gl014687

[6] Kothawale, D.R. and Rupa Kumar, K. (2005) On the Recent Changes in Surface Temperature Trends over India. Geophysical Research Letters, 32, L18714. http://dx.doi.org/10.1029/2005gl023528

[7] Kothawale, D.R., Munot, A.A. and Krishna Kumar, K. (2010) Surface Air Temperature Variability over India during 1901-2007 and Its Association with ENSO. Climate Research, 42, 89-104. http://dx.doi.org/10.3354/cr00857

[8] Kumar, K.K., Patwardhan, S.K., Kulkarni, A., Kamala, K., Koteswara Rao, K. and Jones, R. (2011) Simulated Projections for Summer Monsoon Climate over India by a High-Resolution Regional Climate Model (PRECIS). Current Science, 101, 312-326.

[9] Kothawale, D.R., Krishna Kumar, K. and Srinivasan, G. (2012) Spatial Asymmetry of Temperature Trends over India and Possible Role of Aerosols. Theoretical and Applied Climatology, 110, 263-280. http://dx.doi.org/10.1007/s00704-012-0628-8

[10] Halpert, M.S. and Ropelewaski, C.F. (1992) Surface Temperature Patterns Associated with the Southern Oscillation. Journal of Climate, 5, 577-593. http://dx.doi.org/10.1175/1520-0442(1992)005<0577:STPAWT >2.0.CO;2

[11] Chowadhary, J.S., John, N. and Ganaseelan, C. (2014) Interannual Variability of Surface Air-Temperature over India: Impact of ENSO and Indian Ocean Sea Surface Temperature. International Journal of Climatology, 34, 416-429. http://dx.doi.org/10.1002/joc.3695

[12] Rupa Kumar, K. and Hingane, L.S. (1988) Long Term Variations of Surface Air Temperature at Major Industrial Cities of India. Climatic Change, 13, 287-307. http://dx.doi.org/10.1007/BF00139811

[13] Dhorde, A. and Gadgil, A.S. (2004) Long Term Temperature Trends at Four Largest Cities of India during the Twentieth Century. Journal of Indian Geophysical Union, 13, 85-97.

[14] Rao, P.G.S., Jaswal, A.K. and Kumar, M.S. (2004) Effects of Urbanization on Meteorological Parameters. Mausam, 55, 429-440.

[15] Mohan, M., Kandya, A. and Battiprolu, A. (2011) Urban Heat Island Effect over National Capital Region of India: A Study Using the Temperature Trends. Journal of Environmental Protection, 2, 465-472. http://dx.doi.org/10.4236/jep.2011.24054 
[16] Jaganathan, A. and Andimuthu, R. (2013) Temperature Trends of Chennai City, India. Theoretical and Applied Climatology, 111, 417-425. http://dx.doi.org/10.1007/s00704-012-0646-6

[17] Census of India (2011) The Registrar General and Census Commissioner.

[18] Ren, G., Zhou, Y., Chu, Z., Zhou, J., Zhang, A., Guo, J. and Liu, X. (2008) Urbanization Effect on Observed Surface Air Temperature Trends in North China. Journal of Climate, 21, 1333-1348. http://dx.doi.org/10.1175/2007JCLI1348.1

[19] Kothawale, D.R. and Rupa Kumar, K. (2002) Tropospheric Temperature Variation over India and Links with the Indian Summer Monsoon 1971-2000. Mausam, 53, 289-308.

[20] Ramanathan, V. and Ramana, M.V. (2005) Persistent, Widespread, and Strongly Absorbing Haze over the Himalayan Foothills and the Indo-Ganges Basins. Pure and Applied Geophysics, 162, 1609-1626. http://dx.doi.org/10.1007/s00024-005-2685-8

[21] Singh, D., Buchunde, P.S., Singh, R.P., Nath, A., Sarvan, K. and Ghodpage, R.N. (2014) Lighting and Convective Rain Study in Different Parts of India. Atmospheric Research, 137, 35-48. http://dx.doi.org/10.1016/j.atmosres.2013.09.018

[22] Lal, D.M., Ghude S.D., Patil S.D., Kulkarni, S.H., Jena, C., Tiwari, S. and Srivastava M (2012) Tropospheric Ozone and Aerosol Long-Term Trends over the Indo-Gangetic Plain (IGP), India. Atmospheric Research, 116, 82-92. http://dx.doi.org/10.1016/j.atmosres.2012.02.014

[23] Wilbanks, T.J. and Kates, R.W. (1999) Global Change in Local Places: How Scale Matters. Climatic Change, 43, 601628. http://dx.doi.org/10.1023/A:1005418924748

[24] Sen Roy, S., Mahmood, R., Niyogi, D., Lei, M., Foster, S.A., Hubbard, K.G., Douglas, E. and Pielke, R. (2007) Impacts of the Agricultural Green Revolution-Induced Land Use Changes on Air Temperatures in India. Journal of Geophysical Research, 112, Article ID: D21108. http://dx.doi.org/10.1029/2007jd008834

\section{Submit or recommend next manuscript to SCIRP and we will provide best service for you:}

Accepting pre-submission inquiries through Email, Facebook, LinkedIn, Twitter, etc.

A wide selection of journals (inclusive of 9 subjects, more than 200 journals)

Providing 24-hour high-quality service

User-friendly online submission system

Fair and swift peer-review system

Efficient typesetting and proofreading procedure

Display of the result of downloads and visits, as well as the number of cited articles

Maximum dissemination of your research work

Submit your manuscript at: http://papersubmission.scirp.org/ 